\title{
Análise Microestrutural e Cristalográfica da Fratura de Corpos de Prova de Impacto Charpy-V da Região de Grãos Grosseiros da ZAC Simulada de Aço TMCPa
}

\author{
Tadeu Messias Donizete Borba ${ }^{1}$ (D) , Odair José dos Santos ${ }^{1}$, Paulo José Modenesi² \\ ${ }^{1}$ Centro de Pesquisa \& Desenvolvimento da Usiminas - Usiminas, Ipatinga, MG, Brasil. \\ 2 Universidade Federal de Minas Gerais - UFMG, Departamento de Engenharia Metalúrgica e de Materiais, Belo Horizonte, MG, Brasil.
}

Como citar: Borba TMD, Santos OJ, Modenesi PJ. Análise Microestrutural e Cristalográfica da Fratura de Corpos de Prova de Impacto Charpy-V da Região de Grãos Grosseiros da ZAC Simulada de Aço TMCP. Soldagem \& Inspeção. 2020;25:e2505. https://doi.org/10.1590/0104-9224/SI25.05

\begin{abstract}
Resumo: Nesse trabalho investigou-se a fratura de corpos de prova de impacto Charpy-V da região de grãos grosseiros da zona afetada pelo calor (GGZAC) de dois aços de $355 \mathrm{MPa}$ de limite de escoamento. Um dos aços foi produzido por laminação controlada seguida de resfriamento acelerado (TMCP - Thermomechanical Controlled Process) e outro por laminação convencional seguida por tratamento térmico de normalização. As GGZACs estudadas foram produzidas em condições de soldagem de elevado aporte térmico através da simulação termomecânica no equipamento Gleeble. As análises foram efetuadas em seção transversal ao plano de fratura dos corpos de prova, utilizando técnicas de microscopias óptica e eletrônica de varredura com detector de difração de elétrons retroespalhados (EBSD - Electron Backscatter Diffraction) acoplado. Foi observado que o tamanho de grão, próximo à fratura, da austenita prévia do aço TMCP foi consideravelmente menor do que o do aço convencional e que a unidade de fratura por clivagem relacionou-se a estruturas de menor dimensão, presentes internamente ao grão austenítico. Por meio de EBSD, verificou-se que o aço TMCP apresentou uma densidade superior de contornos de grão de alto ângulo e pacotes cristalográficos menores quando comparado com o aço convencional, fatores esses que favorecem a resistência ao impacto Charpy- $V$ do material. Essas características podem estar associadas ao efeito de ancoramento do grão austenítico por precipitados coerentes de TiN.
\end{abstract}

Palavras-chave: GGZAC; Aços TMCP; Gleeble; Ensaio de Impacto Charpy-V; EBSD.

\section{Microstructural and Crystallographic Analysis of the Charpy-V Impact Specimens Fracture of Simulated Coarse Grain HAZ Region of TMCP Steel}

\begin{abstract}
This work investigated the fracture of Charpy-V Impact test specimens of weld coarse grained heat affected zone (CGZAC) of two $355 \mathrm{MPa}$ class steels. One of the steels was produced by controlled rolling followed by accelerated cooling (TMCP - Thermo-mechanical-Controlled-Process) and another by conventional rolling followed by normalizing heat treatment. The CGZACs were produced by termo-mechanical simulation in the Gleeble equipment under high thermal input welding conditions. The analyzes were carried out in cross section of the fracture plane, using optical and scanning electron microscopy applying Electron Backscatter Diffraction (EBSD) technique. It was observed that the grain size of the previous austenite, close to fracture of the TMCP steel, was considerably smaller than that of the conventional steel and that the cleavage fracture unit was related to smaller structures present inside the austenitic grain. By means of EBSD, it was verified that TMCP steel presented a higher density of high angle grain boundary and smaller crystallographic packages when compared to conventional steel, factors that improve the Charpy-V impact resistance of the material. These characteristics may be associated with the pinning effect of the austenitic grain by coherent TiN precipitates.
\end{abstract}

Key-words: CGHAZ; TMCP Steels; Gleeble; Charpy-V Impact Test; EBSD.

\section{Introdução}

Nas últimas décadas, a soldagem com elevado aporte de calor tem sido usada como alternativa para otimização dos processos de união de aços em diversas aplicações [1-8]. Como exemplo, na indústria naval asiática utiliza-se o processo arco submerso tandem unilateral tanto na linha de painelização, quanto na união entre blocos [6-8]. No setor de estruturas, os

a XLVCONSOLDA - Congresso Nacional de Soldagem, Camboriú, SC de 28 a 31 de outubro de 2019. 
japoneses constroem viadutos e pontes empregando os processos a arco submerso unilateral e eletrogás [8-10]. Para a fabricação da maioria de suas torres eólicas, a China e a Coréia do Sul produzem os tramos metálicos aplicando processos de soldagem de alta eficiência, possibilitando a deposição de dois passes em um chanfro duplo V [11-14].

Durante a soldagem com elevado aporte térmico, regiões do metal de base próximas ao cordão de solda são expostas a elevadas temperaturas $\left(\sim 1350{ }^{\circ} \mathrm{C}\right)$ e seguidas por uma relativa baixa velocidade de resfriamento [7,15,16]. Como consequência, a zona afetada pelo calor (ZAC), próxima à linha de fusão, é sujeita a um elevado crescimento do grão da austenita prévia (TGx) e, durante o resfriamento, ocorrem transformações que resultam na formação de constituintes frágeis e de alta temperatura de transformação. Nessa região da ZAC, denominada de grãos grosseiros (GGZAC), em um aço estrutural convencional submetido a elevado aporte de calor, geralmente são observados constituintes como a ferrita de contorno de grão (FC) e a de segunda fase alinhada (FS), com uma quantidade considerável do constituinte MA (martensita/austenita) [17-20]. O maior TG tenacidade por serem sítios preferenciais para a nucleação de fratura do tipo clivagem, a qual tem sua propagação facilitada através desses constituintes por apresentarem contornos de baixo ângulo [18,21,22]. Sendo assim, a presença dessas regiões, também conhecidas como zonas de fragilização localizada (LBZs - Local Brittle Zones) [15,18], por afetar negativamente a integridade e confiabilidade do componente soldado, deve ser minimizada.

Dessa forma, durante a soldagem com elevado aporte de calor, a estratégia mais eficaz para potencializar a formação de constituintes tenazes, inibir o crescimento do grão austenítico e da região de GGZAC, é a utilização dos aços TMCP (Thermomechanical Controlled Process) que possuem finos precipitados de TiN em sua matriz $[6-9,15,17,18]$ especialmente desenvolvidos para aperfeiçoar a sua soldabilidade [1,5,18,23-25]. Dentre os precipitados encontrados em aços microligados, o mais estável nas temperaturas da GGZAC é o TiN, Figura 1a. No entanto, essas partículas somente serão efetivas no ancoramento (efeito pinning) dos contornos de grãos da austenita, Figura $1 b$, se as mesmas forem coerentes, homogeneamente distribuídas e com um diâmetro médio inferior a $400 \mathrm{~nm}$, o que só é possível para a relação Ti/N entre 2,0 e 3,4, Figura 1c [7-9,17,18,26,27]. A prática industrial para produzir aços com tais características é um processo complexo sendo um diferencial competitivo de cada empresa que detém tal tecnologia.

Para a geração de conhecimentos e divulgação acerca dos benefícios da utilização de aços TMCP soldados com alto aporte térmico, em um primeiro trabalho [17], avaliaram-se o crescimento de grão da austenita prévia e a susceptibilidade à formação do constituinte MA na região de GGZAC de um aço TMCP de 355 MPa de limite de escoamento (LE) comparativamente a outro, de mesma classe de LE, porém processado de forma convencional (CONV). Foi constatado que o aço CONV, em relação ao aço TMCP, apresentou, para condições de elevado aporte de calor (baixa velocidade de resfriamento), uma maior susceptibilidade a formação de constituinte frágil MA na GGZAC, além de um considerável maior TGx.

Continuando na formação e divulgação de conhecimentos técnicos relativos aos efeitos do aporte térmico na soldabilidade dos aços estruturais/navais, no presente estudo objetivou-se avaliar o efeito de um elevado aporte de calor na resistência ao impacto Charpy-V e nas características cristalográficas da região de GGZAC simulada dos aços avaliados no trabalho anterior [17].

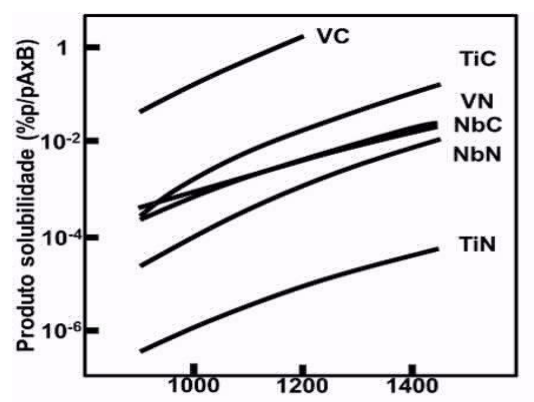

(a) Solubilização de precipitados na GGZAC.

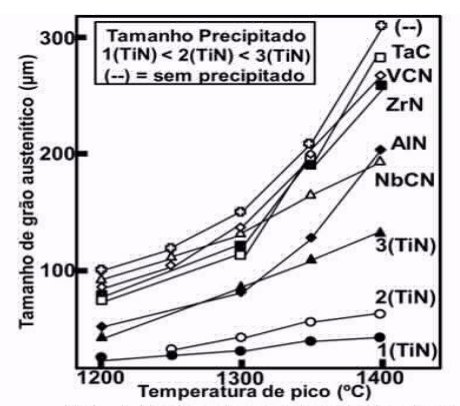

(b) Efeito dos precipitados no TGy.

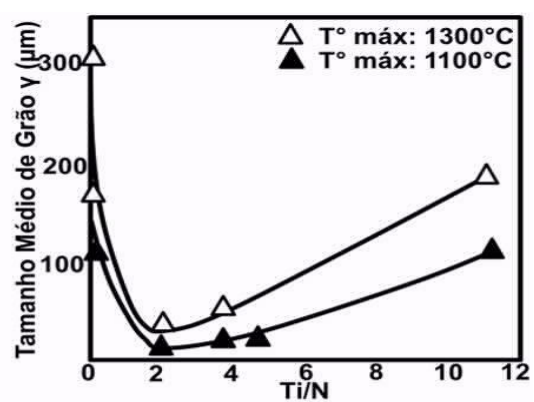

(c) Relação Ti/N e TGy.

Figura 1. Efeito da presença de TiN no tamanho de grão austenítico da GGZAC. TGy = tamanho de grão médio da austenita prévia. $T^{\circ}$ máx: temperatura máxima ou de pico avaliada. Adaptado de $[26,27]$. Ilustração: autor.

\section{Materiais e Métodos}

\subsection{Materiais}

Foram avaliados dois aços de $355 \mathrm{MPa}$ de limite de escoamento, de $35 \mathrm{~mm}$ de espessura, produzidos em escala industrial utilizando: (i) laminação controlada seguida de resfriamento acelerado (UHHIW - Aço Ultra High Heat Input Welding) e; (ii) laminação convencional seguida de tratamento térmico de normalização (Aço convencional - CONV). São materiais 
utilizados nos setores eólico e naval/offshore, portanto, atendem os requisitos da norma EN-10025 (CONV: parte 2; UHHIW: parte 4) [28,29] e do grau naval EH36 [30]. Nas Tabelas 1 e 2 são apresentadas a composição química e as propriedades dos aços estudados, análises estas executadas no estudo [17].

Tabela 1. Composição química dos aços UHHIW e CONV (\% p/p) [17]

\begin{tabular}{|c|c|c|c|c|c|c|c|}
\hline Aço & C & Mn & Si & $\mathbf{P}$ & $S$ & Al & $\mathrm{Ca}$ \\
\hline UHHIW & 0,09 & 1,38 & 0,22 & 0,012 & 0,0009 & 0,033 & 0,0016 \\
\hline \multirow[t]{2}{*}{ CONV } & 0,16 & 1,42 & 0,18 & 0,020 & 0,0020 & 0,035 & 0,0021 \\
\hline & $\mathrm{Ni}+\mathrm{Cr}+\mathrm{Cu}+\mathrm{Nb}+\mathrm{V}$ & $\mathrm{Ti}$ & & & $\mathrm{Ti} / \mathrm{N}$ & $\mathrm{Ceq}^{(\mathrm{a})}$ & $\mathrm{Pcm}^{(\mathbf{b})}$ \\
\hline UHHIW & 0,10 & 0,010 & & & 2,37 & 0,32 & 0,17 \\
\hline CONV & 0,11 & 0,020 & & & 5,13 & 0,41 & 0,24 \\
\hline
\end{tabular}

Nota: $(a): \mathrm{Ceq}=\mathrm{C}+\mathrm{Mn} / 6+(\mathrm{Ni}+\mathrm{Cu}) / 15+(\mathrm{Cr}+\mathrm{Mo}+\mathrm{V}) / 5[31] ;(b): \mathrm{Pcm}=\mathrm{C}+\mathrm{Si} / 30+(\mathrm{Mn}+\mathrm{Cu}+\mathrm{Cr}) / 20+\mathrm{Ni} / 60+\mathrm{Mo} / 15+\mathrm{V} / 10+5 B[31]$.

Tabela 2. Valores de propriedades mecânicas e resistência ao impacto Charpy-V dos aços UHHIW e CONV [17].

\begin{tabular}{|c|c|c|c|}
\hline Aço & Limite de Escoamento (MPa) ${ }^{a}$ & Limite de Resistência (MPa)a & Alongamento (\%) ${ }^{a, b}$ \\
\hline UHHIW & $408 \pm 6$ & $513 \pm 8$ & $31 \pm 2$ \\
\hline CONV & $416 \pm 3$ & $541 \pm 7$ & $23 \pm 3$ \\
\hline Espec. EN10025 (2\&4) & $\geq 345$ & $470-630$ & $\geq 21$ \\
\hline Espec. EH 36 & $\geq 345$ & $490-620$ & $\geq 15$ \\
\hline \multirow[t]{2}{*}{ Aço } & \multicolumn{2}{|c|}{ 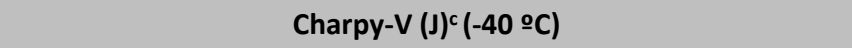 } & Especificação \\
\hline & & EN10025 (2\&4) & EH 36 \\
\hline UHHIW & $433 \pm 2$ & $31 \mathrm{~J}\left(-40^{\circ} \mathrm{C}\right)$ & \multirow{2}{*}{$34 \mathrm{~J}\left(-40^{\circ} \mathrm{C}\right)$} \\
\hline CONV & $147 \pm 39$ & $27 \mathrm{~J}\left(-20^{\circ} \mathrm{C}\right)$ & \\
\hline
\end{tabular}

Nota: (a): valor médio de três corpos de prova; (b) Base de Medida $=50 \mathrm{~mm}$; (c) valor médio de cinco corpos de prova ensaiados na temperatura de $-40{ }^{\circ} \mathrm{C}$.

\subsection{Amostragem e simulação dos ciclos térmicos de soldagem}

Confeccionaram-se 6 corpos de prova (CPs) de seção quadrada de $10 \times 10 \mathrm{~mm}$ com $105 \mathrm{~mm}$ de comprimento (direção de laminação), os quais foram amostrados a $1 / 4$ da espessura de chapas industriais dos aços avaliados. Todos os CPs foram submetidos à simulação física no equipamento Gleeble empregando o mesmo ciclo térmico de soldagem, de forma a reproduzir a GGZAC de juntas soldadas com elevado aporte de calor $(330 \mathrm{~kJ} / \mathrm{cm}$ ) e com um único passe de solda.

A programação do ciclo térmico de soldagem foi realizado no módulo HAZ do próprio software de controle do equipamento. Para a simulação, foi empregada a expressão de Rykalin 2D (Equação 1), uma das primeiras soluções analíticas para as equações diferenciais de fluxo de calor considerando fontes de calor móveis [32]. Como dados de entrada, foi utilizado $25{ }^{\circ} \mathrm{C}$ para a temperatura inicial $\left(\mathrm{T}_{0}\right), 100{ }^{\circ} \mathrm{C} / \mathrm{s}$ para a velocidade de aquecimento, $1350{ }^{\circ} \mathrm{C}$ para a temperatura de pico $\left(\mathrm{T}^{\circ} \mathrm{p}\right)$, $2 \mathrm{~s}$ para o tempo de permanência nessa temperatura e 500 s para o tempo de resfriamento entre 800 e $500{ }^{\circ} \mathrm{C}(\Delta \mathrm{t} / 5 / 5)$. Para os parâmetros do processo de soldagem que se deseja simular foi utilizado 1 para o rendimento térmico $(\eta), 330 \mathrm{~kJ} / \mathrm{cm} \mathrm{para} \mathrm{o}$ aporte térmico (AT) e $35 \mathrm{~mm}$ para a espessura (h) da junta soldada da qual deseja-se reproduzir o ciclo térmico de soldagem nos CPs da Gleeble. Além dessas informações, é necessário inserir certas características dos materiais como a densidade ( $\rho)$, condutividade térmica $(\mathrm{k})$ e calor específico $(\mathrm{c})$. Como tais propriedades físicas variam com a temperatura, foram utilizados valores encontrados na literatura [33], na qual se utilizou materiais e metodologia de ensaio semelhante aos empregados nesse trabalho. $\mathrm{O}$ ciclo térmico reproduzido é ilustrado na Figura $2 \mathrm{a}$.

$\Delta_{t 8 / 5}=\left(\frac{1}{4 \pi k \rho c}\right)\left(\frac{\eta \mathrm{AT}}{h}\right)^{2}\left(\frac{1}{\left(500-T_{0}\right)}\right)^{2}-\left(\frac{1}{\left(800-T_{0}\right)}\right)^{2}$

Onde: $\mathrm{AT}:(330 \mathrm{~kJ} / \mathrm{cm}) ; \eta=1 ; \mathrm{k}=0,5 \mathrm{~W} / \mathrm{cm}^{\circ} \mathrm{C} ; \rho=7,8 \mathrm{~g} / \mathrm{cm}^{3} ; \mathrm{c}=1 \mathrm{~J} / \mathrm{g}^{\circ} \mathrm{C} ; \mathrm{T}_{0}=25^{\circ} \mathrm{C} ; \mathrm{h}=35 \mathrm{~mm} ; \Delta \mathrm{t}_{8 / 5}=500 \mathrm{~s}$. 


\subsection{Avaliação da resistência ao impacto Charpy-V da GGZAC simulada}

O ensaio de impacto Charpy- $V$ foi realizado conforme a norma ASTM A370-17A [34], na temperatura de $-40{ }^{\circ} \mathrm{C}$ (temperatura especificada para os aços avaliados na condição mais crítica estipulada para o grau naval EH36) nos CPs submetidos à simulação termomecânica, os quais foram redimensionados para o tipo full size (10 x $10 \times 55 \mathrm{~mm})$, com o entalhe posicionado logo abaixo da região do termopar de controle, Figura $2 \mathrm{~b}$.
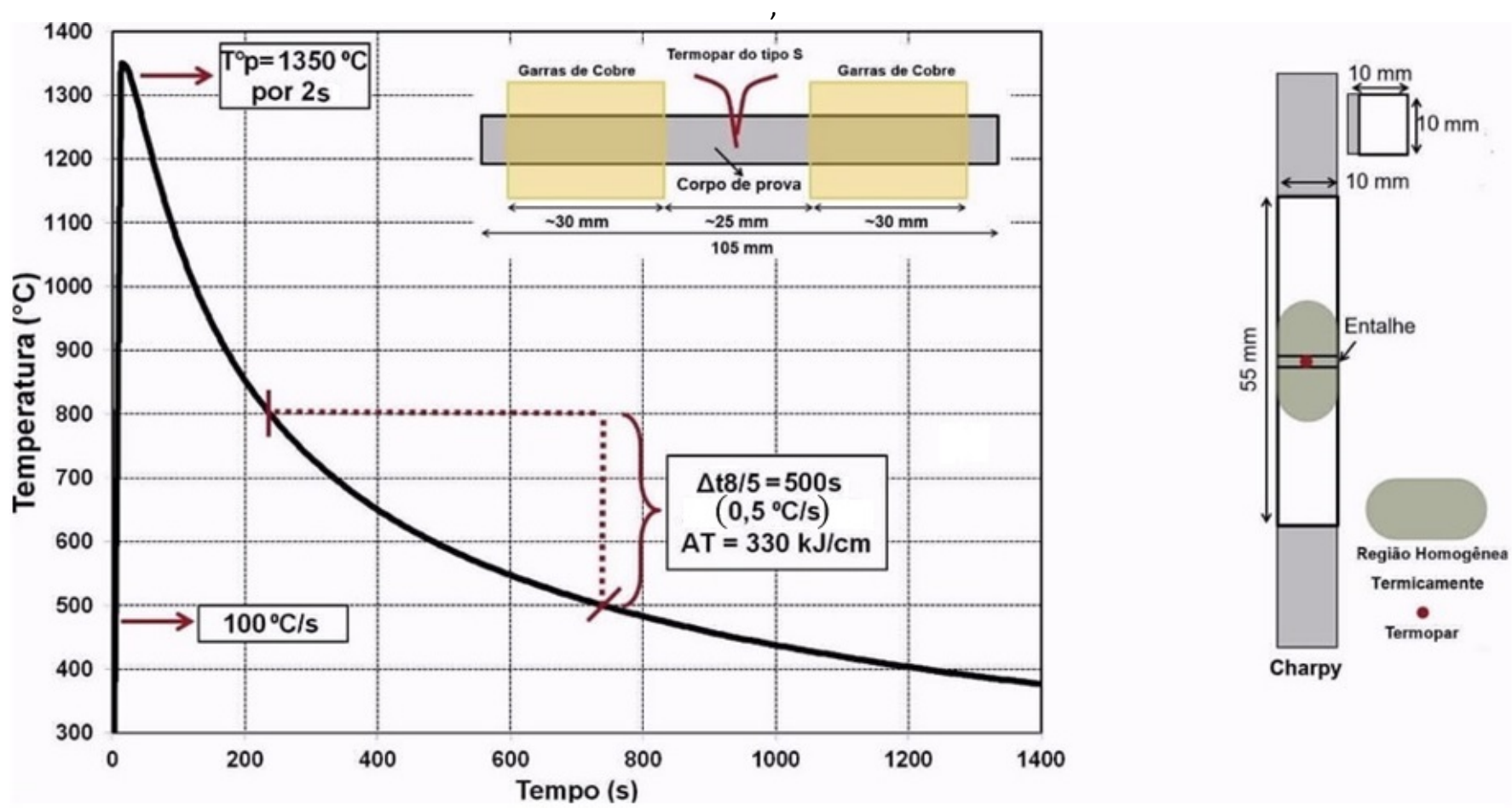

(a) Ciclo térmico simulado

(b) Corpo de prova utilizado

Figura 2. Ilustração esquemática (a) do ciclo térmico de elevado aporte de calor avaliado e (b) das dimensões dos CPs simulados na Gleeble.

\subsection{Análise fractográfica}

Após o ensaio de impacto Charpy-V, foi realizada a medição, via o software ImageJ, da fração de fratura dúctil e da expansão lateral de todos os CPS ensaiados conforme a norma ASTM E23-18 [35]. Também foi realizado a análise, via microscopia eletrônica de varredura (MEV), da superfície de fratura dos CPs ensaiados, objetivando a identificação do tipo de fratura e a medição qualitativa das eventuais facetas de clivagem.

\subsection{Análise microestrutural e cristalográfica em plano transversal à superfície de fratura}

Com o objetivo de correlacionar o tamanho das facetas de clivagem e o caminho preferencial de propagação da fratura, foram realizadas análises metalográfica e cristalográfica em seção transversal ao plano da fratura de alguns CPs de impacto Charpy-V. Para tal, essa etapa foi realizada em três fases:

(i) Recobrimento dos CPs de impacto Charpy-V fraturados: a superfície de fratura foi recoberta com níquel por eletrodeposição para evitar o abaulamento da fratura no momento do seccionamento e polimento dos CPs. As condições de eletrodeposição, as mesmas realizadas no trabalho de Alé [18], são descritas na Tabela 3. Após a eletrodeposição de níquel, as amostras foram seccionadas conforme ilustrado na Figura 3. 
Tabela 3. Procedimento utilizado para a realização do recobrimento dos CPs com níquel.

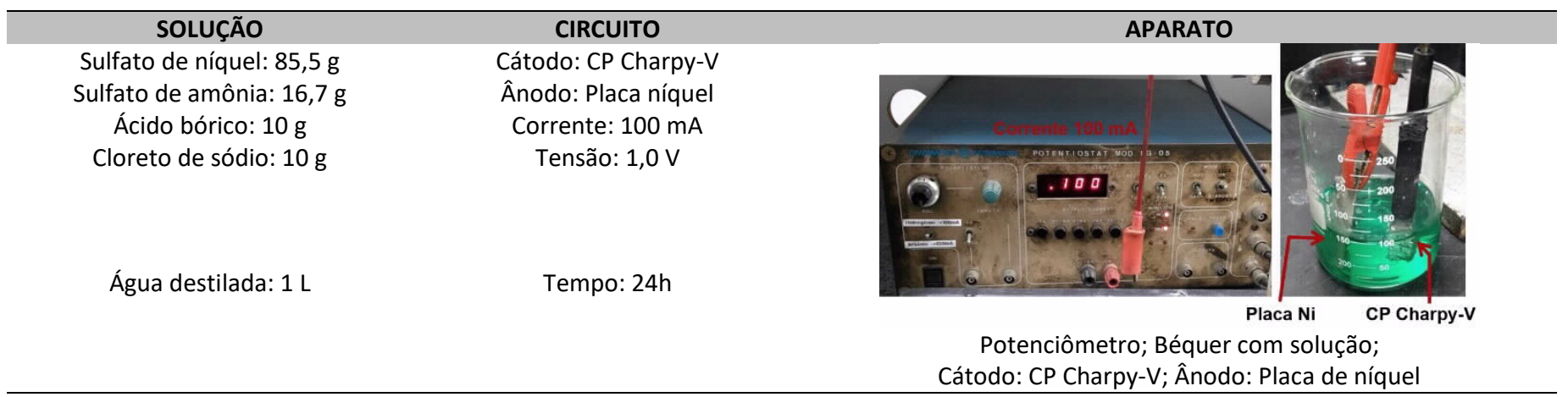

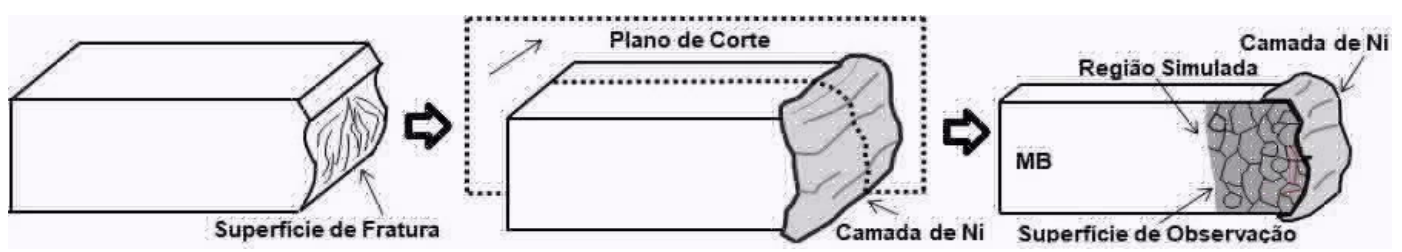

Figura 3. Condições e aparato para a realização do recobrimento dos CPs de Charpy com níquel e ilustração esquemática de corte dos CPs para análise metalográfica.

(ii) Análise microestrutural: a superfície do plano de corte então foi preparada no modo convencional e atacada com nital 4\% para revelar a microestrutura. Para revelar os contornos dos grãos austeníticos (CGү) foram testados vários ataques químicos, conforme descrito na literatura [36]. O reativo que apresentou os melhores resultados foi a solução Pipal modificado ( $16 \mathrm{~g}$ de $\mathrm{CrO}_{3} / 80 \mathrm{~g}$ de $\mathrm{NaOH}$ em $145 \mathrm{ml}$ de água destilada e 6 gotas de $\mathrm{HCl}$ ), aplicada após a realização de polimento eletrolítico com sílica coloidal em suspensão.

(iii) Análise cristalográfica: a microestrutura ao longo do plano ortogonal à propagação da fratura dos CPs de Charpy-V também foi caracterizada em termos de orientação cristalográfica, utilizando um microscópio eletrônico de varredura capaz de realizar análise de EBSD. Para tal, as amostras foram preparadas via polimento eletrolítico utilizando sílica coloidal em suspensão. As análises foram realizadas posicionando as amostras a uma distância de trabalho de 17,5 mm e com um ângulo de inclinação de $70^{\circ}$ em relação ao feixe de elétrons incidente e $20 \mathrm{kV}$ de tensão. Os elétrons retroespalhados geram padrões de difração que são capturados por uma tela de fósforo posicionada no interior da câmara de vácuo e transmitidos a um detector (fabricante HKL) os quais são processados através do software HKL fast acquisition 2007 e comparados com os padrões de raias pré-estabelecidos de Kikuchi (padrão de difração dos elétrons retroespalhados). Para as GGZAC dos dois aços avaliados, foram determinados a variação do grau de desorientação cristalográfica, a variação do tamanho das unidades cristalográficas e os mapas de figura de polo inversa (IPF - Inverse Pole Figure) empregando um step size de 0,5 $\mu \mathrm{m}$ e varrendo 8 campos.

De forma resumida, na Figura 4 é ilustrada a sequência experimental das principais etapas executadas durante a realização desse trabalho. 
SIMULAÇÃO DO CICLO TÉRMICO DE SOLDAGEM VIA GLEEBLE

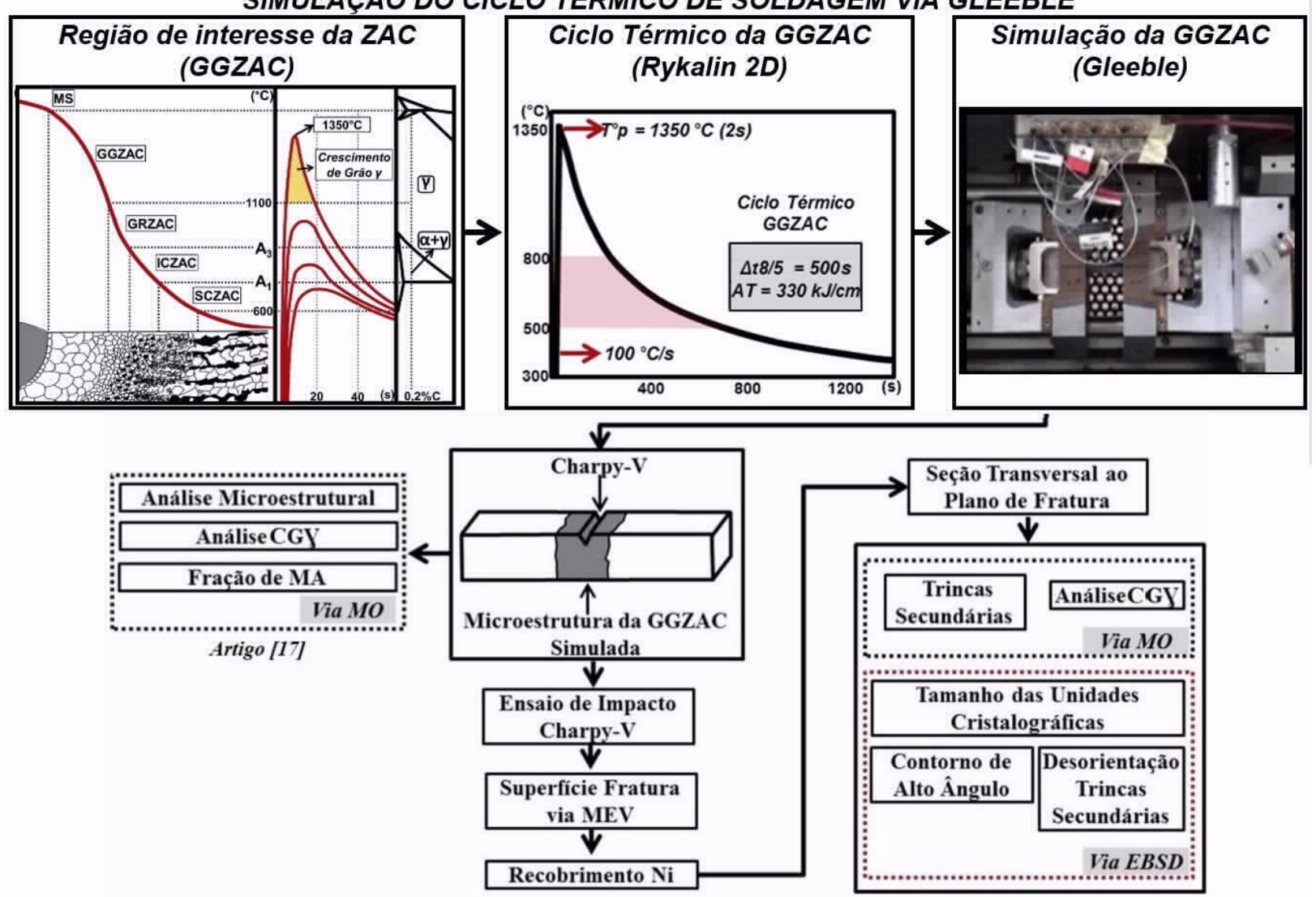

Figura 4. Fluxograma dos experimentos executados nesse trabalho.

\section{Resultados e Discussão}

\subsection{Ensaio de impacto Charpy-V e análise fractográfica}

Na Figura 5 são apresentados os resultados do ensaio de impacto Charpy-V. Verifica-se que a energia absorvida do aço UHHIW (189 $\pm 31 \mathrm{~J})$ é muito superior à obtida para o aço CONV (17 $\pm 5 \mathrm{~J})$, quando submetidos às mesmas condições de simulação e de temperatura de ensaio. Ainda na Figura 5, observa-se que todos os CPs do aço UHHIW apresentam um início de fratura predominantemente dúctil (área dúctil quantificada via ImageJ na superfície de fratura dos CPs UHHIW $=43 \pm 4 \%$ ), uma região intermediária no centro dos CPs com aspecto cristalino (área cristalina quantificada via ImageJ na superfície de fratura dos CPs UHHIW $=50 \pm 6 \%$ ) e um término fibroso, característico do rasgamento final da fratura (área de rasgamento final quantificada via ImageJ na superfície de fratura dos CPs UHHIW = $7 \pm 2 \%$ ), acompanhado por uma considerável expansão lateral $(1,7 \pm 0,2 \mathrm{~mm}$ ou $19 \pm 2 \%)$. Já os CPs do aço CONV apresentam um aspecto de fratura predominantemente cristalina, sem evidência de regiões dúcteis e nem expansão lateral. 

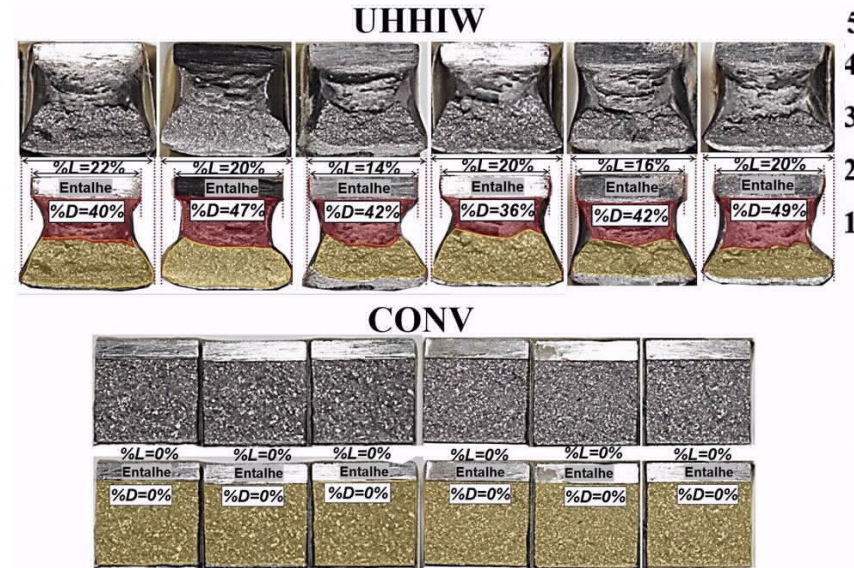
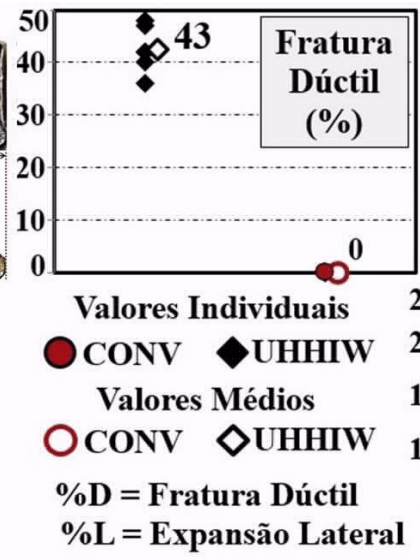
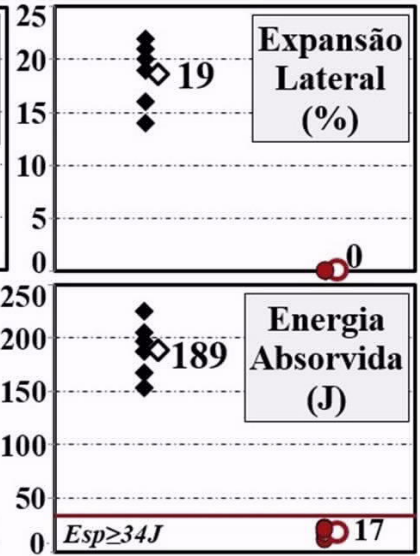

Figura 5. Resultados do ensaio de impacto Charpy-V realizados nos CPs da GGZAC simulados na Gleeble na condição $\Delta \mathrm{t}_{8 / 5}=500 \mathrm{~s}$. Temperatura de ensaio: $-40^{\circ} \mathrm{C}$. Energia absorvida especificada para os aços em questão: $34 \mathrm{~J}$.

Analisando as superfícies de fratura via MEV, apresentadas na Figura 6, constata-se que na região de iniciação da fratura (abaixo da ponta do entalhe), o aço UHHIW apresenta modo de fratura do tipo dúctil com a presença de inúmeras cavidades (dimples). Nessa mesma região, o aço CONV apresenta facetas de clivagem ( $\left.F_{C L}\right)\left(F_{C L}\right.$ CONV $=4386 \pm 129 \mu m^{2} ; n=33$ ), indicando a característica frágil da microestrutura desse aço quando submetido à condição $\Delta$ t $8 / 5=500$ s de resfriamento. Já na região central dos CPs do aço UHHIW, a fratura apresenta aspecto misto ou de quasi-clivagem, com microcavidades (dimples) intercaladas com pequenas facetas de clivagem ( $F_{C L}$ UHHIW $=1347 \pm 49 \mu \mathrm{m}^{2} ; n=33$ ). No caso do aço CONV, o centro dos CPs apresenta-se frágil, com algumas facetas de clivagem de grandes dimensões (maiores $F_{C L}$ na fratura dos CPs do aço CONV: $\mathrm{F}_{\mathrm{CL}} \mathrm{CONV}=41791 \pm 491 \mu \mathrm{m}^{2} ; \mathrm{n}=12$ ), além de trincas secundárias em planos ortogonais à fratura.
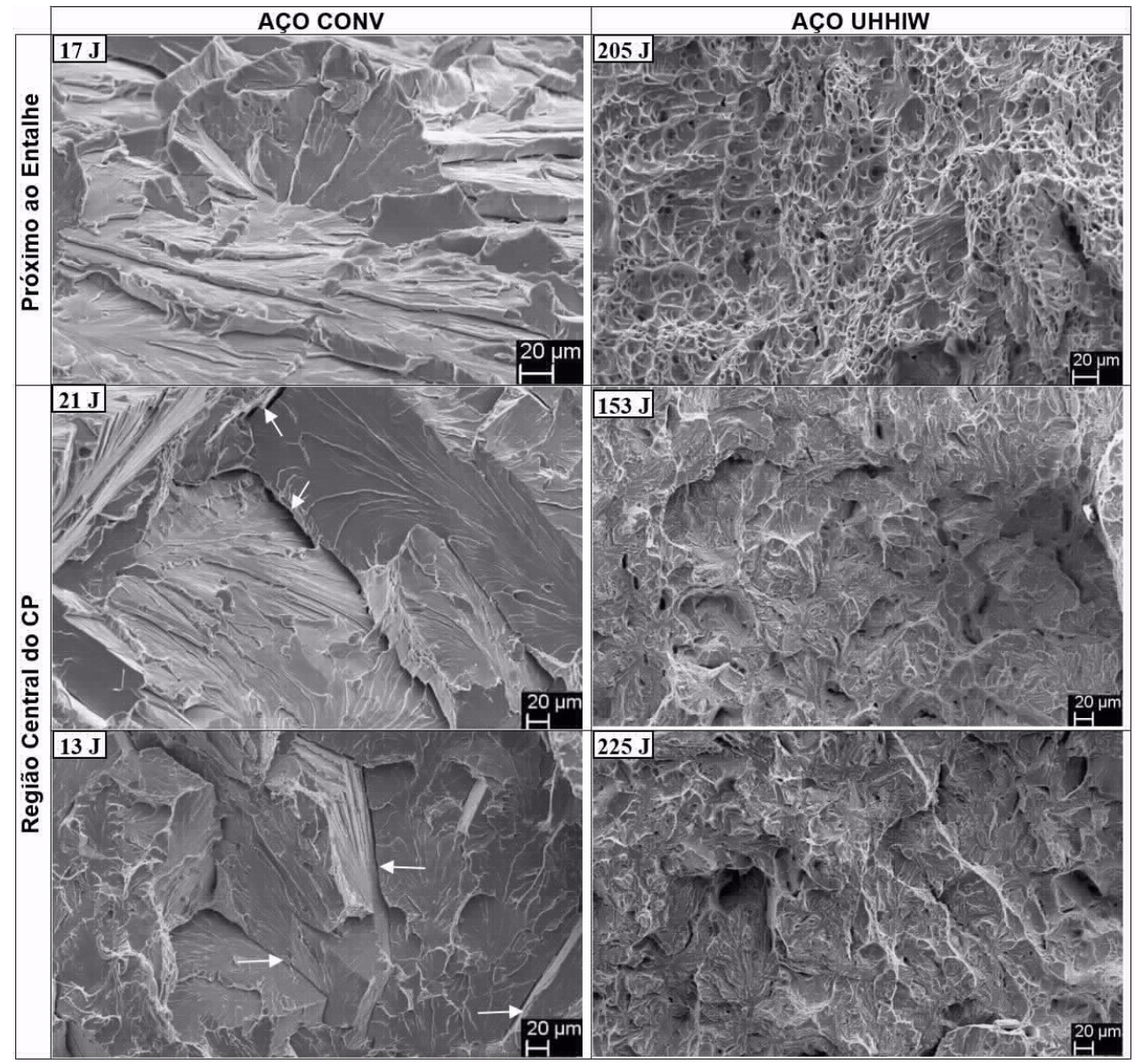

Figura 6. Superfície de fratura de alguns CPs de Charpy-V da GGZAC simulados na Gleeble na condição $\Delta \mathrm{t}_{8 / 5}=500$ s observados via $\mathrm{MEV}$. Setas brancas: trincas secundárias. 


\subsection{Análise microestrutural via MO e cristalográfica via EBSD em seção transversal ao plano de fratura}

Após o ensaio de impacto Charpy- $V$, foi selecionado um dos CPs do aço UHHIW (187 J) e do aço CONV (17 J) para avaliação das características microestruturais e cristalográficas em regiões da seção transversal ao plano de propagação da fratura. Na Figura 7 é possível visualizar os contornos de grãos austeníticos (CGү), próximo à região de fratura, dos CPs selecionados. Observa-se, tanto para o aço CONV, quanto para o aço UHHIW, regiões com diferentes tamanhos de grãos austeníticos. A natureza heterogênea do grão austenítico que, segundo Borba e Modenesi [17], segue uma distribuição do tipo log-normal está associada ao crescimento competitivo, em temperaturas superiores a $1100{ }^{\circ} \mathrm{C}\left(\mathrm{GGZAC} 1450-1100{ }^{\circ} \mathrm{C}\right)$, de alguns grãos em detrimento a outros. O tamanho dos grãos austeníticos (TGY) do aço CONV é, qualitativamente, superior ao TG $\gamma$ do aço UHHIW e essa diferença foi atribuída ao efeito pinning por precipitados de TiN.

Além das diferenças significativas do TGy (setas vermelhas), na Figura 7 também é possível observar a presença de deformação plástica (setas verdes) e a existência de trincas secundárias (setas brancas) associadas à fratura. Para o aço CONV foram observadas 42 trincas secundarias associadas à trinca principal e nenhuma trinca secundária para o material UHHIW. Abaixo do entalhe (início da fratura), verifica-se uma considerável deformação plástica do aço UHHIW, o que não é observado no aço CONV. Essas são duas características que também auxiliam no entendimento da variação da resistência ao impacto Charpy-V da GGZAC entre os aços UHHIW e CONV. Praticamente toda a extensão da fratura do aço UHHIW apresenta um aspecto dúctil (setas verdes), ao contrário da propagação retilínea e com poucos desvios da trinca do aço CONV, característica da fratura frágil por mecanismo de clivagem. Esse fato está relacionado, no caso do aço UHHIW, conforme evidenciado por Borba e Modenesi [17], à formação de uma microestrutura de menor dureza, de maior ductilidade e de maior tensão de fratura (menor TGy), quando comparado ao aço CONV.

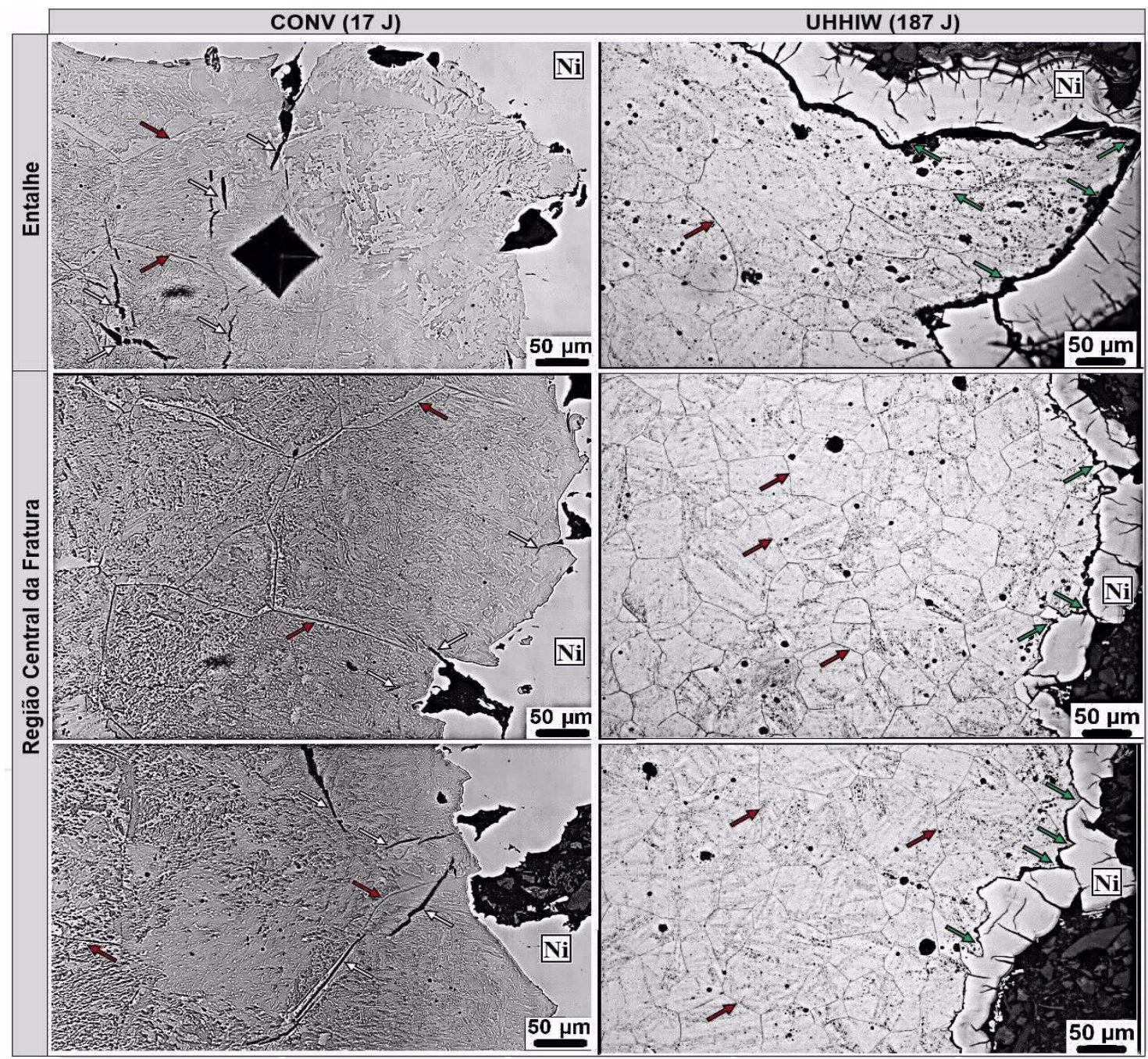

Figura 7. Seção transversal ao plano de propagação da fratura. Análise via MO após polimento eletrolítico e ataque com reativo pipal modificado. Seta vermelha: CGy; Seta branca: trincas secundárias; Seta verde: deformação. 
As características microestruturais e cristalográficas de regiões próximas à fratura e com a presença de trincas secundárias podem prover informações úteis para estudar os mecanismos envolvidos na formação e propagação da fratura ocorrida por clivagem. A análise via EBSD é uma técnica que possibilita obter informações cristalográficas em regiões ortogonais ao plano de fratura [37-39]. Trincas secundárias são aquelas que, após sua nucleação, são desviadas ou embotadas em contornos de alto ângulo (CAA), em pequenos grãos ou em pacotes-unidades cristalográficas [40]. Existem muitos trabalhos que caracterizam trincas frágeis através da técnica EBSD [37-45] e nesse trabalho avaliou-se a seção transversal ao plano de propagação de fratura do aço CONV. A elevada deformação plástica observada na seção transversal do CP de Charpy-V UHHIW proporcionou uma baixa indexação dos parâmetros EBSD e, portanto, para esse material, as análises foram realizadas em regiões distantes da fratura de forma a comparar as orientações cristalográficas desse material com as do aço CONV.

Os resultados das análises via EBSD, realizadas na GGZAC simulada dos aços em questão, são apresentados na Figura 8 através da variação do grau de desorientação, dos mapas IPFs e dos correspondentes mapas com contornos de grão superiores a $45^{\circ}$. As variações de cores nos mapas IPFs evidenciam as alterações na orientação de pacotes ou unidades cristalográficas (UC) de uma determinada região. O grau de desorientação é a diferença na orientação entre duas UC adjacentes em um material policristalino. Em termos físicos, a desorientação é a transformação ou rotação necessária para transpor um sistema de coordenadas de um determinado cristal para um sistema de coordenadas de um segundo cristal. Segundo a literatura [38,46-48], uma matriz com contornos de grãos de alto ângulo (CAA > $15^{\circ}$ ) favorecem a tenacidade do material, porém, $C A A \geq 45^{\circ}$ são os mais efetivos para elevar a resistência à fratura por clivagem e dificultar a propagação de microtrincas. Já as unidades cristalográficas de contornos de baixo grau de desorientação $\left(\leq 15^{\circ}\right)$ são os principais responsáveis por controlar as propriedades em tração do material, como o limite de escoamento (LE) e de resistência (LR) por atuarem como barreiras ao movimento das deslocações [49-51].

Analisando a Figura 8, observa-se, para os dois aços, que o grau de desorientação apresenta uma distribuição bimodal com picos nas faixas de contornos de baixo e alto ângulo. O aço UHHIW apresenta uma quantidade superior (58\%) de subestruturas com CAA em comparação ao aço CONV (28\%), o que, de certa forma, auxilia no entendimento da superioridade, em termos de resistência ao impacto Charpy-V, da GGZAC do aço UHHIW em relação à do aço CONV. Além disso, verifica-se que as GGZACs avaliadas apresentam praticamente as mesmas quantidades (CONV = 40\%; UHHIW = 39\%) de contornos de baixo ângulo $\left(\leq 15^{\circ}\right)$ e, dessa forma, é possível que ambos os materiais apresentem comportamento semelhante quando submetidos ao ensaio de tração. 

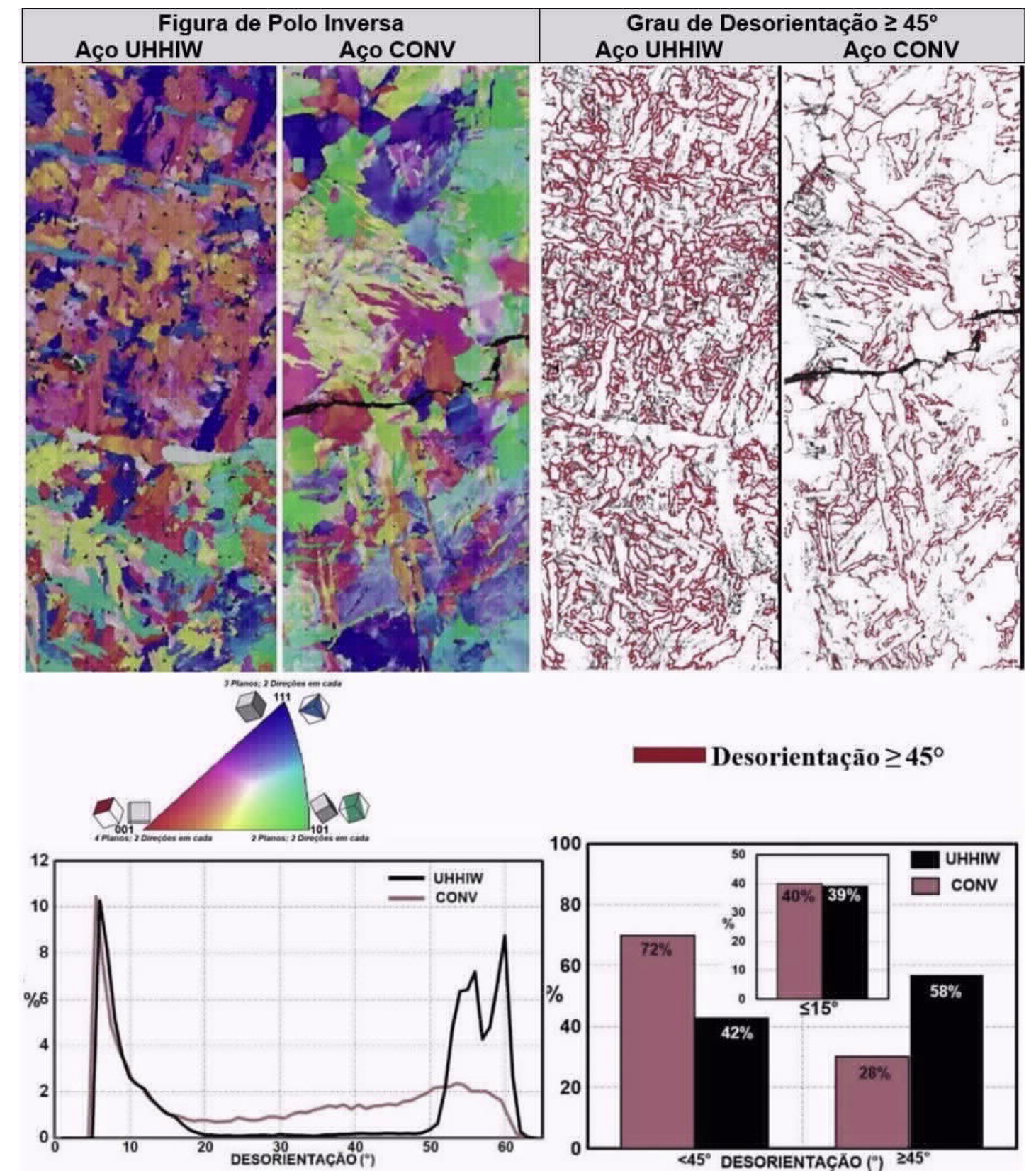

Desorientação $\geq 45^{\circ}$

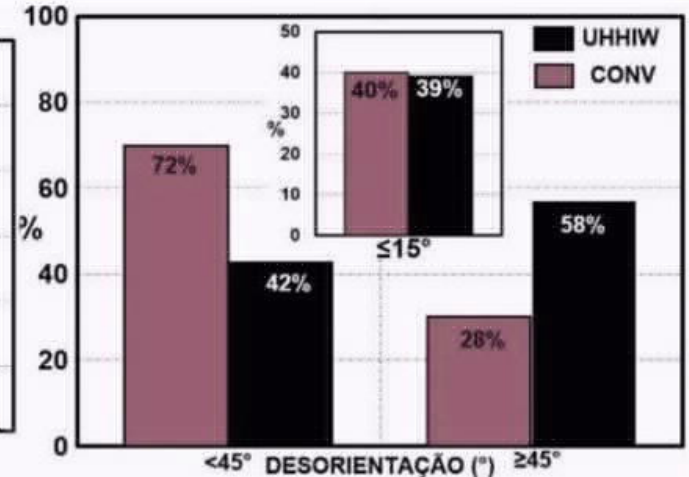

Figura 8. Análise via EBSD (step size $=0,5 \mu \mathrm{m}$ ) nos CPs simulados na condição $\Delta \mathrm{t}_{8 / 5}=500$ s dos aços CONV e UHHIW.

Na Figura 9 são apresentadas as medições de área e do diâmetro das UC detectadas na análise via EBSD nas regiões representadas na Figura 8, utilizando como parâmetro o grau de desorientação $\geq 15^{\circ}$. Assim como o tamanho de grão da austenita prévia apresentada no trabalho anterior [17], as UC também apresentam distribuições do tipo log-normal, para as variações de área e diâmetro. Observa-se que a GGZAC do aço UHHIW possui uma estrutura mais refinada do que o aço CONV, com 55\% das UC com áreas inferiores a $6 \mu \mathrm{m}^{2}$ (diâmetro inferior a $3 \mu \mathrm{m}$ ), em comparação aos $57 \%$ das UC do aço CONV com áreas superiores a $12 \mu \mathrm{m}^{2}$ (diâmetro superior a $6 \mu \mathrm{m}$ ).

A obtenção de um menor tamanho de grão da austenita prévia na GGZAC do aço UHHIW, simulada em condições de baixa velocidade de resfriamento $\left(0,5{ }^{\circ} \mathrm{C} / \mathrm{s}\right)$, favorece a formação de subestruturas ou pacotes internos (UC) ao grão austenítico de menores tamanhos quando comparado aos do aço CONV. A formação de UC menores (aço UHHIW) dentro de um mesmo grão austenítico e pertencentes a grupos diferentes de variantes de Bain beneficiam a formação de contornos de alto ângulo devido ao encontro desses pequenos pacotes cristalinos [39]. 


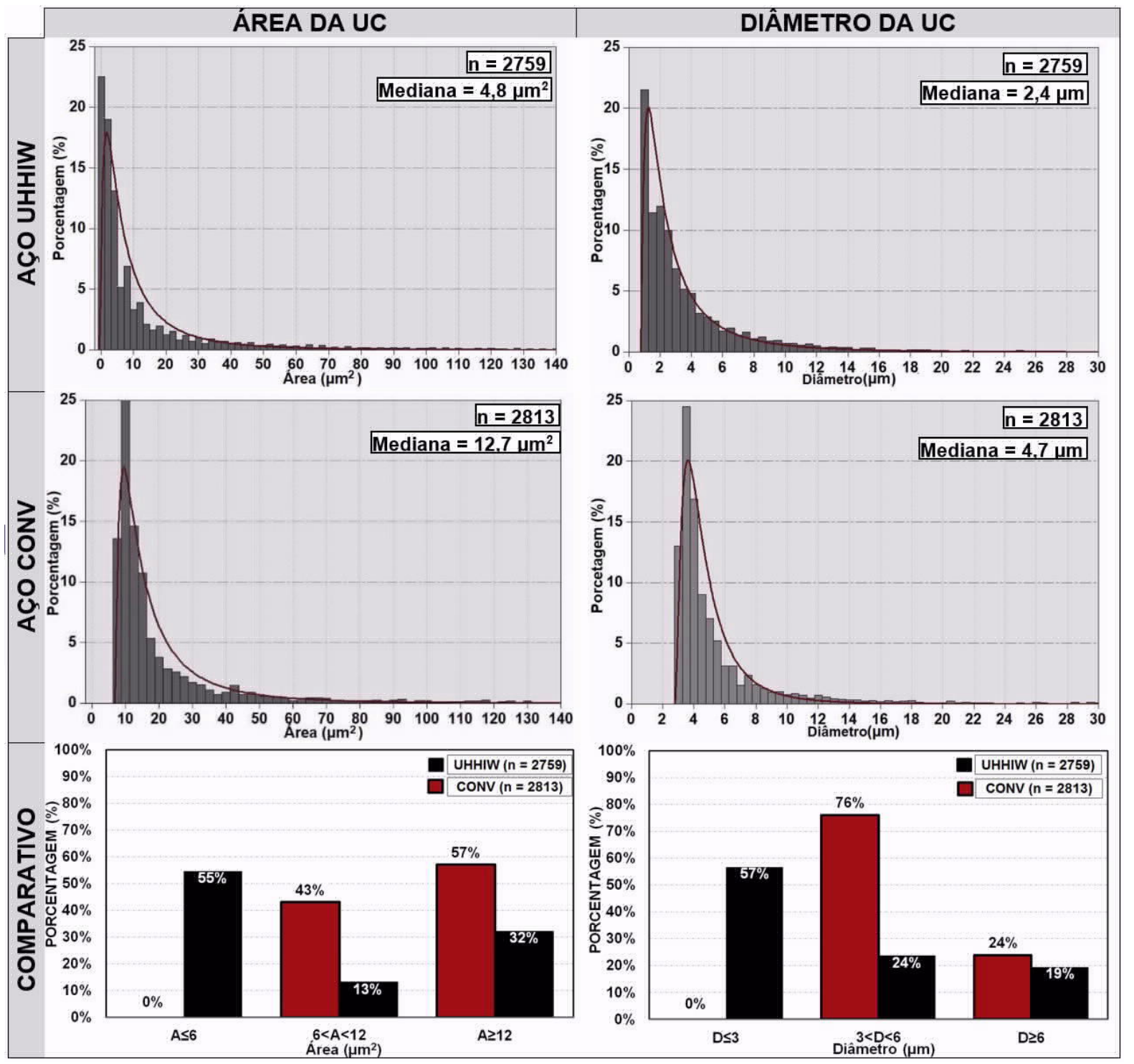

Figura 9. Distribuição da área e do diâmetro médio das unidades cristalográficas(UC) das GGZAC simuladas.

Na Figura 10 são apresentados os resultados das análises metalográficas e cristalográficas realizadas via MO e MEV/EBSD em regiões com e sem a presença de trincas secundárias, que propagam ortogonalmente ao caminho da trinca principal (fratura) em um dos CPs de Charpy-V (17 J) do aço CONV. Primeiramente, é possível verificar que os desvios na propagação da trinca principal, que definem as facetas de clivagem observadas na superfície de fratura, estão mais relacionados com os pacotes de mesma orientação cristalográfica do que com o próprio tamanho de grão austenítico (TGү). Isso indica que a unidade que retarda a propagação da trinca frágil ou grão efetivo [18] são as unidades cristalográficas (UC), ao invés dos grãos comumente revelados por ataques metalográficos e observados via MO ou MEV. Também é possível observar que microconstituintes morfologicamente semelhantes, observados via $\mathrm{MO}$, e caracterizados como ferrita com segunda fase não alinhada (FS), apresentam características cristalográficas diferentes, com baixo (1) e alto (2) grau de desorientação interna. Esse é um exemplo de que constituintes com o mesmo aspecto microestrutural podem apresentar características cristalográficas diferentes e, portanto, propriedades mecânicas distintas.

As trincas secundárias, identificadas como A e B, se originam na interface entre a ferrita de contorno de grão (FC) e um constituinte acicular, possivelmente ferrita de Widmanstätten intragranular (WI) de contornos de alto ângulo ( $\geq 45^{\circ}$ linhas vermelhas), e propagam sem um apreciável desvio pela ferrita de contorno de grão (FC) de baixo grau de desorientação $\left(<10^{\circ}\right)$. Especificamente para a trinca $A$, desvios sucessivos de seu caminho ocorrem após a sua transposição do CGy devido à presença de pacotes de alto grau de desorientação. $O$ final da propagação da trinca B ocorre com o seu embotamento em um CG , onde há a interseção de duas unidades cristalinas de diferentes orientações (identificadas pelas cores rosa e azul), formando um contorno com grau de desorientação superior a $50^{\circ}$. A interrupção da propagação da trinca $B$ pode ter ocorrido devido: 
- A não existência de planos preferenciais, $\{100\}$, para a continuação de sua propagação da UC de tonalidade verde (FC) para a UC de tonalidade rosa (possivelmente em uma WI). Todos os possíveis planos apresentam elevada desorientação, com o plano de propagação da trinca exigindo, dessa forma, uma elevada energia para rotacionar a próxima UC via cisalhamento.

- A presença de UC menores. De acordo com Griffith [52], a tensão de fratura do grão é inversamente proporcional a raiz quadrada de seu diâmetro. Portanto, para uma trinca propagar através de UC menores, necessariamente a tensão resultante aplicada deve ser superior à exigida para fraturar UC maiores.

É possível verificar que as trincas secundárias ocorrem em regiões com a presença de ferrita de contorno de grão (FC), com segunda fase (FS) alinhada e não alinhada, com baixa densidade de contornos de alto ângulo, ou seja, com reduzida capacidade de retardar/bloquear a propagação das trincas por clivagem. Uma vez nucleadas não há uma densidade considerável de contornos de alto ângulo para impedir a sua propagação, que ocorre facilmente ao longo de todo o grão que, além da principal família de planos $\{100\}$, segundo Naylor [53] também podem propagar através dos planos $\{110\}$, $\{112\}$ e $\{123\}$, porém em menor probabilidade.

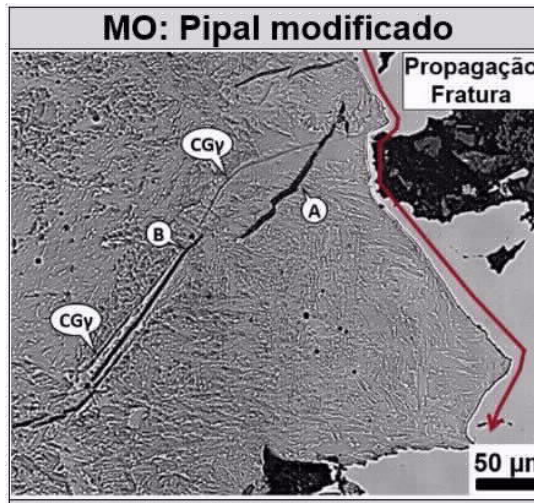

EBSD: IPF
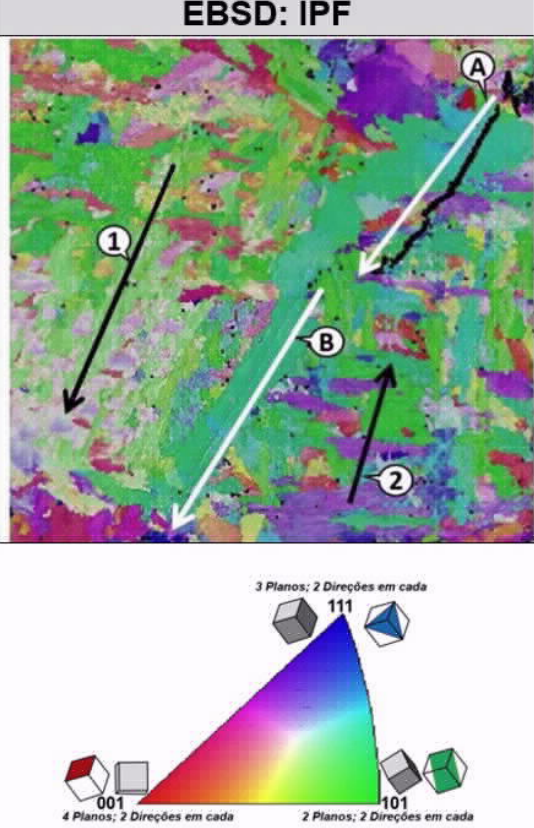

Ângulo de Desorientação $\geq 45^{\circ}$

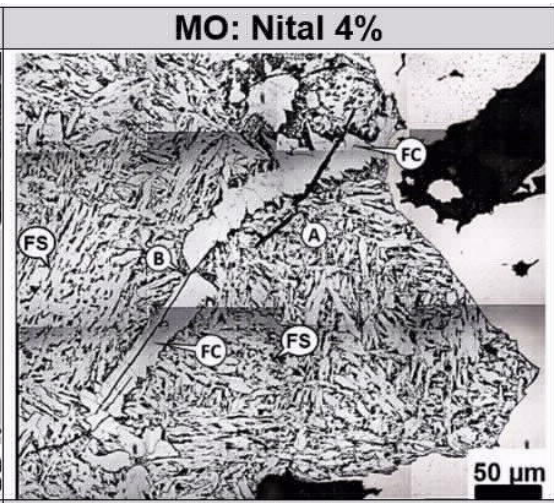

EBSD: Desorientação $\geq 45^{\circ}$

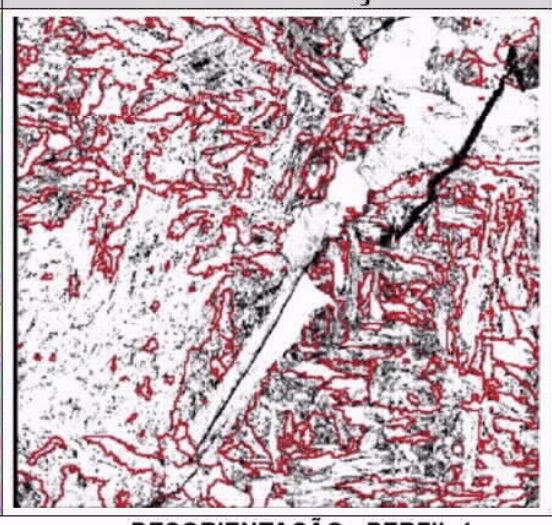

DESORIENTACÃO - PERFIL

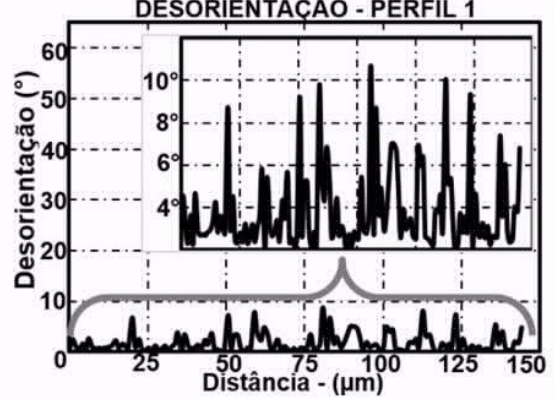

TRINCA SECUNDÁRIA (A)

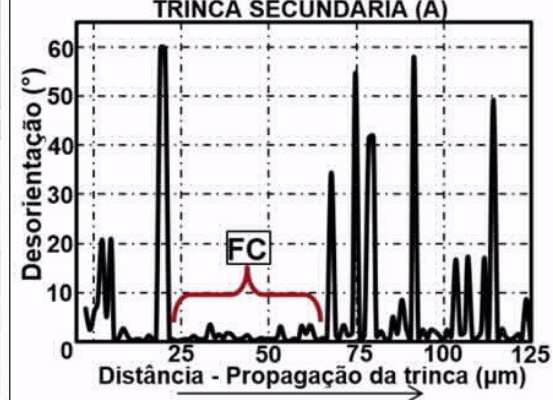

TRINCA SECUNDÁRIA (B)

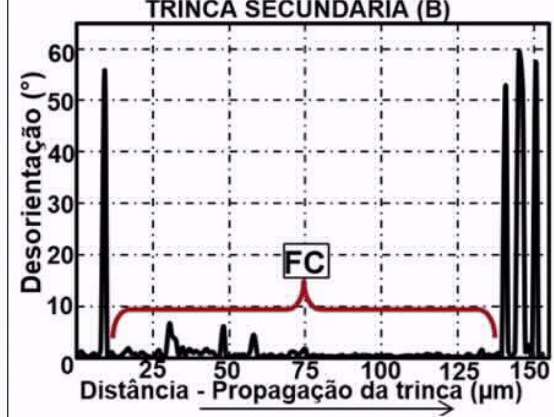

DESORIENTAÇÃO - PERFIL 2

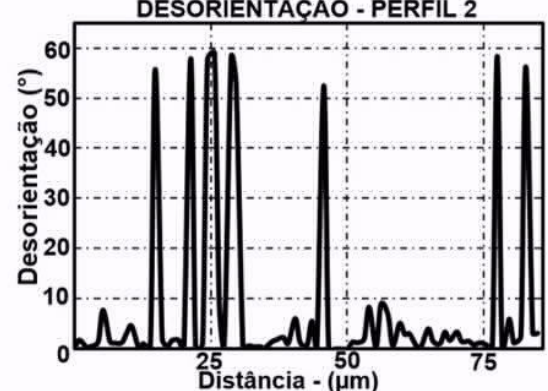

Figura 10. Seção transversal ao plano de fratura do CP simulados na condição $\Delta \mathrm{t}_{8 / 5}=500$ s do aço CONV. Análise via MO. Ataque com reativo nital $4 \%$ e pipal modificado. Análise via MEV/EBSD (step size $=0,5 \mu \mathrm{m}$ ), evidenciando os mapas de IPF e de desorientação superior a $45^{\circ}$, além do perfil de desorientação próximo $(A, B)$ e distantes $(1,2)$ a trincas secundárias.

Quando a trinca principal ultrapassa os CAA, observou-se que a maioria dos ângulos de deflexão da propagação da fratura concentra-se entre 20 e $55^{\circ}$, sendo, em algumas poucas regiões, observados ângulos superiores a $60^{\circ}$. Na Figura 11 são apresentadas algumas regiões ao longo da propagação da trinca de clivagem em que estão presentes pacotes de alto grau de 
desorientação, porém, não são observados desvios apreciáveis no caminho da fratura. A propagação da fratura ocorre em três dimensões e os mapas de desorientação obtidos via EBSD são visualizados em duas dimensões. Dessa forma, deve-se levar em consideração que o plano de propagação das trincas de clivagem geralmente é ortogonal ao plano de análise. Na Figura 12, então, são ilustradas as possíveis variações na propagação da trinca de clivagem em relação ao grau de desorientação e ao plano de análise.

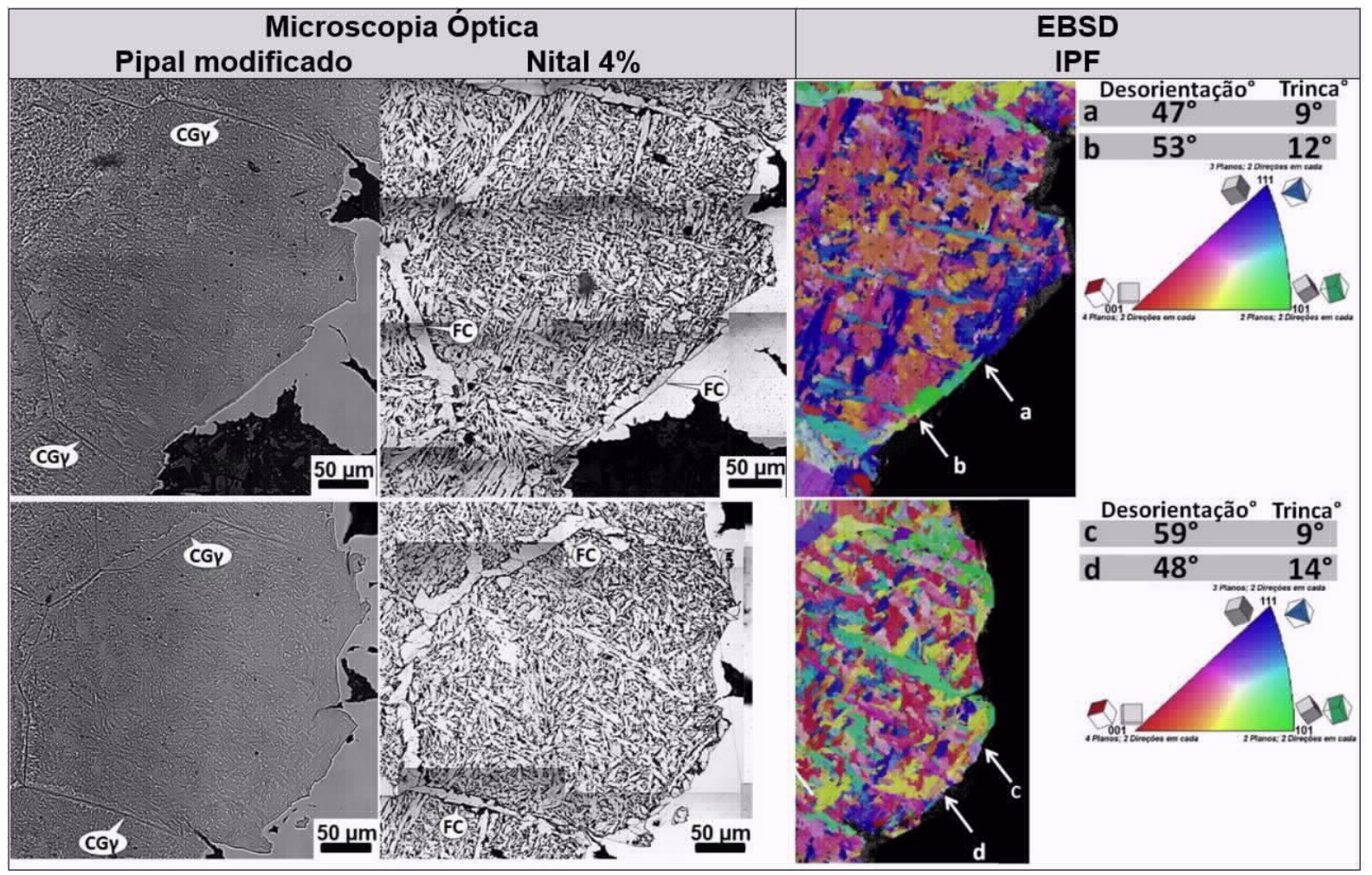

Figura 11. Regiões com baixo desvio na propagação da trinca em regiões de elevado grau de desorientação. Condição $\Delta \mathrm{t}_{8 / 5}=500 \mathrm{~s}$ do aço CONV. Análise via MO, após polimento eletrolítico e ataque com reativo nital $4 \%$ e pipal modificado, e via EBSD (step size $=0,5 \mu \mathrm{m})$.

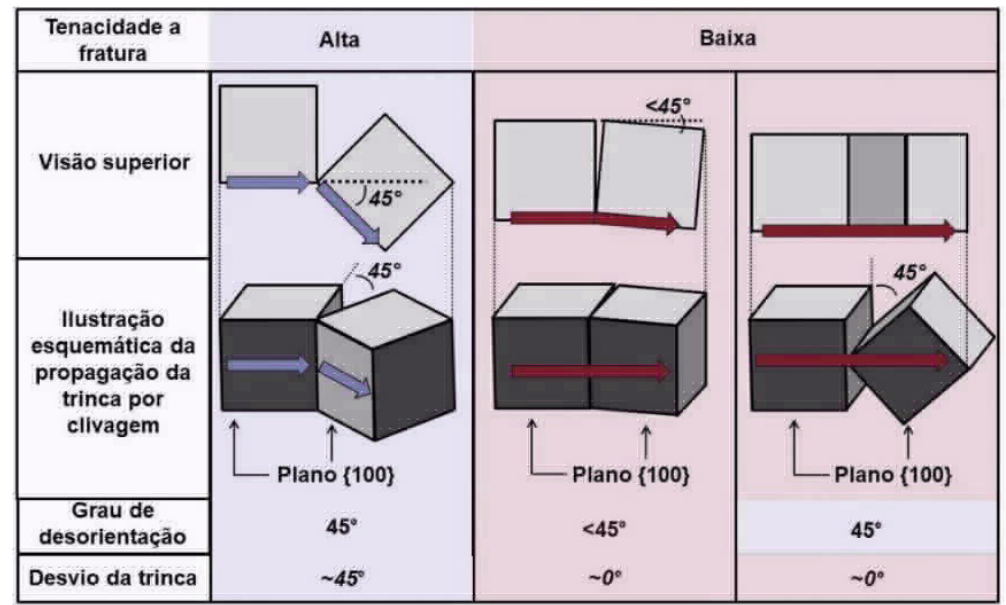

Figura 12. Ilustração esquemática da propagação de trincas frágeis de clivagem em relação ao grau de desorientação. Adaptado de Shirahata et al. [54]. Ilustração: autor.

Dessa forma, através dos resultados do estudo [17] e das análises realizadas nesse trabalho, na Figura 13 é ilustrado o sequenciamento de um possível mecanismo para a explicar a propagação das fraturas observadas na GGZAC simulada na Gleeble na condição $\Delta t_{8 / 5}=500$ s para os aços CONV e UHHIW. 
Acredita-se que menores grãos austeníticos (TG $\mathrm{T}$ ) favorecem a formação de unidades cristalográficas (UC) menores, as quais, por suas vezes, contribuem para o aumento da fração de contornos de alto ângulo (CAA). Segundo a literatura [38,46-49], CAA dificultam a propagação de eventuais trincas de clivagem e contribuem para a redução do grão efetivo, favorecendo, dessa forma, a tenacidade do material.

Por outro lado, maiores grãos austeníticos (TGY), potencializam a formação de maiores UC, reduzindo a probabilidade de ocorrência de CAA. Uma menor fração de CAA "facilita" a propagação de trincas por clivagem, reduzindo, por sua vez, a tenacidade da GGZAC. Além disso, uma fração relativamente elevada de MA na GGZAC do aço CONV $(2,24 \pm 0,24 \%)$ em relação ao aço UHHIW $(0,26 \pm 0,04 \%)$ observadas em associação à ferrita de contorno de grão e/ou com segunda fase alinhada potencializa a fragilização microestrutural, conforme apresentado em [17].

Comparando os aços avaliados, desconsiderando os valores de Ceq (CONV =0,41; UHHIW = 0,32) e o tipo de processamento (CONV = laminação convencional e normalização; UHHIW = TMCP) que afetam significativamente a soldabilidade dos mesmos, os autores desse trabalho atribuem as significativas diferenças cristalográficas e de resistência ao impacto Charpy- $V$ dos materiais em questão à possível presença de finos precipitados de TiN. Esses, por sua vez, foram aparentemente efetivos no ancoramento do grão austenítico da GGZAC do aço UHHIW.

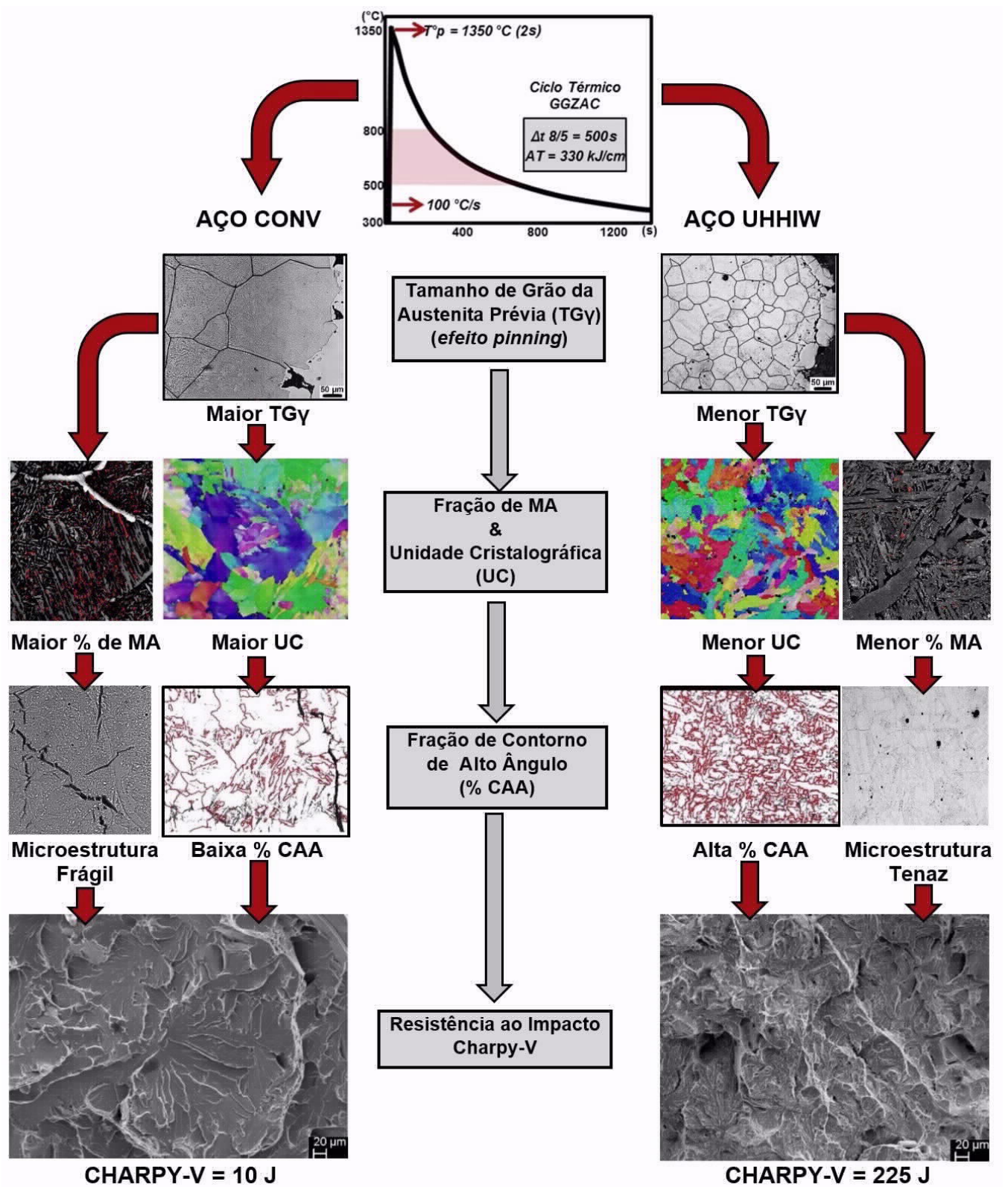

Figura 13. Ilustração sequenciando o possível mecanismo da propagação de fratura na GGZAC simulada na condição $\Delta \mathrm{t}_{8 / 5}=500 \mathrm{~s}$ para os aços CONV e UHHIW. $\mathrm{TG}_{X}=$ Tamanho de grão austenítico prévio. UC = Unidade Cristalográfica. CAA = Contorno de alto ângulo. 


\section{Conclusões}

Neste trabalho avaliou-se o efeito de um elevado aporte de calor na resistência ao impacto Charpy- $V$ e nas características cristalográficas da região de GGZAC simulada dos aços UHHIW e CONV. Os resultados permitiram concluir que:

- A GGZAC simulada do aço UHHIW apresentou energia absorvida superior em relação aos resultados obtidos para a GGZAC simulada do aço CONV. Além disso, verificou-se que a iniciação da fratura no aço UHHIW foi do tipo dúctil, seguida por um aspecto misto, de quasi-clivagem, na região central dos CPs. Já para o aço CONV observou-se que a fratura inicia-se com um aspecto frágil continuada pela formação de grandes facetas de clivagem no centro dos CPs.

- Na seção transversal ao plano de fratura da GGZAC o tamanho de grão austenítico do aço CONV foi qualitativamente superior do que o do aço UHHIW. Essa diferença do TG observada entre os aços foi associada ao efeito pinning dos precipitados de TiN presentes na matriz do aço UHHIW.

- Próximo à propagação da fratura da GGZAC do aço CONV, verificou-se a presença de várias trincas secundárias em comparação com a inexistência das mesmas na matriz da GGZAC do aço UHHIW. Isso é um indicativo da presença de uma microestrutura frágil, de fácil nucleação de microtrincas de clivagem, na GGZAC do aço CONV em relação à microestrutura tenaz da GGZAC do aço UHHIW.

- $\quad$ Através das análises realizadas via EBSD foi possível verificar que a GGZAC do aço UHHIW apresenta uma maior fração de contornos de alto ângulo em relação à GGZAC do aço CONV. Além desse aspecto, a GGZAC do aço UHHIW também possui menores unidades cristalográficas em relação à GGZAC do aço CONV. Segundo a literatura, menores grãos austeníticos favorecem a formação de menores UC que, por sua vez, potencializa a formação de CAA.

- $\quad$ Os mapas de EBSD claramente evidenciaram as alterações da direção de propagação de trincas secundárias da GGZAC do aço CONV em regiões com CAA. Esse fato é um indicativo de que CAA são efetivos na deflexão e embotamento de trincas frágeis e, portanto, a presença de CAA é importante para melhorar a tenacidade de um determinado material.

- $\quad$ Acredita-se que os melhores resultados de resistência ao impacto Charpy-V da GGZAC simulada do aço UHHIW estão associados a maior fração de CAA, a menor UC e ao TGy, devido a presença de finos precipitados de TiN os quais, aparentemente, foram efetivos no efeito de ancoramento do contorno de grão.

- $\quad$ Por fim, o emprego do aço TMCP UHHIW pode ser uma opção para a otimização dos processos de fabricação de torres eólicas, estruturas e de navios de grande porte, por possibilitar a utilização de processos de soldagem de alta eficiência.

\section{Referências}

[1] Imai S. Recent progress and future trends for shipbuilding steel. Welding International. 2008;22(11):755-761. http://dx.doi.org/10.1080/09507110802550661.

[2] ABEEOLICA. [página da internet]. São Paulo: ABEEólica; 2019 [acesso em 11 de janeiro de 2019]. Disponível em: http://www.portalabeeolica.org.br.

[3] Domingues JR. Panorama da Tecnologia da Soldagem na Indústria Naval/Offshore no Brasil Cenário Atual e Tendências. In: Sindicato Nacional da Indústria da Construção e Reparação Naval e Offshore. Anais da 40 Feira e Conferência da Indústria Naval e Offshore NAVALSHORE; 2009; Rio de Janeiro. Rio de Janeiro: NavalShore, 2009, p. 116-127.

[4] Borba TMD, Oliveira RS, Gama HR, Caizer MFO, Turani LO. Avaliação da soldabilidade do Aço Sincron EN 10025-4 S355M aplicado na fabricação de torres eólicas com processo de soldagem de alta deposição. Soldagem \& Inspeção. 2017;22(4):413-428.

[5] Borba TMD, Flores WD, Turani LO, Cardoso R Jr. Assessment of the weldability of EH36 TMCP shipbuilding steel welded by high heat input submerged arc welding. Welding International. 2016;31(3):184-195. http://dx.doi.org/10.1080/09507116.2016.1218619.

[6] Kojima K. Progress in this decade and future prospects of welding technologies on steel plates and pipes. Nippon Steel \& Sumitomo Metal Technical Report. 2018;119:22-25.

[7] Kojima A, Yoshii KI, Hada T, Saeki O, Ichikawa K, Yoshida Y, Shimura Y, Azuma K. Development of high HAZ toughness steel plates for box columns with high heat input welding. Nippon Steel \& Sumitomo Metal Technical Report 2004;90:39-44.

[8] Kojima A, Akihito K, Ryuji U, Masanori M, Manabu H, Takao N, et al. Super high HAZ toughness technology with fine microstructure imparted by fine particles. Nippon Steel \& Sumitomo Metal Technical Report. 2004;90:2-6.

[9] Kojima A, Kasuya T, Tsuruta T, Minami K. Study on application of electrogas arc welding to SM570 steel in bridge fabrication. Doboku Gakkai Ronbunshuu A. 2007;63(1):1-13.

[10] Minami, K, Miki C, Kasuya T, Tsuruta T, Watanabe Y. Evaluation of Charpy impact and fracture toughness properties for bridge high performance steel (BHS500). Doboku Gakkai Ronbunshuu A, 2007;63(1):142. https://doi.org/10.2208/jsceja.63.142. 
[11] Wahlen P. Trends and developments in wind tower fabrication. Istambul: Turkish Constructional Steelwork Association; 2019. [acesso em 27 de ago. 2019]. Disponível em: https://www.tucsa.org/images/yayinlar/sunumlar/Peter-Wahlen.pdf

[12] Asian Biomass Office. Current state of wind power in South Korea. Tokyo; 2019. [acesso em 30 de ago. 2019]. Disponível em: https://www.asiabiomass.jp/english/topics/1310_04.html\#fig1

[13] PR Newswire. Wind Power Industry Trailblazer: MRY Achieves Both EN 1090 EXC3 and ISO 3834-2 Certification. New York: PR Newswire; 2019. [acesso em 30 de ago. 2019]. Disponível em:

https://en.prnasia.com/releases/apac/Wind_Power_Industry_Trailblazer_MRY_Achieves_Both_EN_1090_EXC3_and_ISO_3834_2_Certi fication-183093.shtml

[14] Homma R, Inoue T, Okawa T, Kayamori Y, Shishibori A, Nishimura S. Steel plates and fatigue solution for offshore wind turbines in the fukushima floating offshore wind farm demonstration project. Nippon Steel \& Sumitomo Metal Technical 2015;110:50-57.

[15] Easterling K. Introduction to the Physical metallurgy of Welding. Londres: BMM; 1983. 231 p.

[16] Lan L, Qiu C, Zhao D, Gao X, Du L. Analysis of martensite-austenite constituent and its effect on toughness in submerged arc welded joint of low carbon bainitic steel. Journal of Materials Science. 2012;47(11):4732-4742. http://dx.doi.org/10.1007/s10853-012-6346-x.

[17] Borba TMD, Modenesi PJ. Influência do ciclo térmico de soldagem no crescimento de grão, nas transformações microestruturais e na formação de MA na GGZAC de aço TMCP. Soldagem e Inspeção. 2019;24:e2406. http://dx.doi.org/10.1590/0104-9224/si24.06.

[18] Alé RM. Efeito da Adição de Elementos de Liga (Cu e Ni) nas Propriedades Mecânicas e Microestrutura da ZAC de Aços C-Mn Microligados ao Nb [tese de doutorado]. Rio de Janeiro: COPPE/UFRJ; 1994.

[19] Ikawa H, Oshige H, Tanoue T. Effect of MA Constituent on HAZ Toughness of a High Strength Steel. Journal of the Japan Welding Society. 1980;49(8):532-537. http://dx.doi.org/10.2207/qjjws1943.49.532.

[20] Komizo YI, Fukado Y. CTOD Properties and MA Constituent in HAZ of C-Mn Microalloyed Steel. Quarterly Journal of the Japan Welding Society. 1986;4(2):447-452.

[21] Mao G, Cayron C, Cao R, Logé R, Chen J. The relationship between low-temperature toughness and secondary crack in low-carbon bainitic weld metals. Materials Characterization. 2018;145:516-526. http://dx.doi.org/10.1016/j.matchar.2018.09.012.

[22] Subramani S, Ma X, Wang X, Shang C, Zhang X, Miao C, Collins L. Control of age shear area in DWTT at low temperature in niobium microalloyed line pipe steel. In American Society of Mechanical Engineers. Proceeding of the 12th International Pipeline Conference; 2018 September 24-28; Calgary, Canada. New York: ASME; 2018. p. 10.

[23] Silva RF. Caracterização da zona termicamente afetada de aço produzido via resfriamento acelerado. [dissertação de mestrado]. Belo Horizonte: PPGEM/UFMG; 2010.

[24] Amaral TS. Atlas Microestrutural para Otimização de Procedimentos de Soldagem. Uberlândia: POSMEC/UFU; 2016.

[25] Scotti A, Li H, Miranda RM. Um Round-Robin teste com simulação térmica da ZAC de soldagem para obtenção de diagramas CRC: A necessidade de procedimentos e terminologia de microconstituintes harmonizados. Soldagem e Inspeção. 2014;19(3):279-290. http://dx.doi.org/10.1590/0104-9224/SI1903.11.

[26] Kanazawa S, Nakashima A, Okamoto K, Kanaya K. Improvement of weld fusion zone toughness by fine TiN. Transactions of the Iron and Steel Institute of Japan. 1976;16(9):486-495. http://dx.doi.org/10.2355/isijinternational1966.16.486.

[27] Adrian $\mathrm{H}$, Pickering FB. Effect of titanium additions on austenite grain growth kinetics of medium carbon V-Nb steels containing 0.008 0.018\%N. Materials Science and Technology. 1991;7:176-182. http://dx.doi.org/10.1179/mst.1991.7.2.176.

[28] Deutsches Institut fur Normung. DIN EN 10025-2. Hot Rolled Products of Structural Steels Part 2: Technical Delivery Conditions for NonAlloy Structural Steels. Germany: DIN; 2005.

[29] Deutsches Institut fur Normung. DIN EN 10025-4. Hot Rolled Products of Structural Steels Part 2: Technical Delivery Conditions for Thermomechanical Rolled Weldable Fine Grain Structural Steels. Germany: DIN; 2005.

[30] Lloyd's Register [página da internet]. London, UK: Lloyd's Register Group; 2019 [acesso DAY ago. 2019]. Disponível em: http://www.Ir.org/about_us/

[31] De Meester B. Note on the Carbon Equivalent. Welding in the World. 1990;28(3-4):8-11.

[32] Rykalin R. Energy sources for welding. Welding in the World. 1974;12(9-10):227-248.

[33] Cui B, Peng Y, Zhao L, Peng M, An T, Ma C. Effect of heat input on microstructure and toughness of coarse grained heat affected zone of Q890 Steel. ISIJ International. 2016;56(1):132-139. http://dx.doi.org/10.2355/isijinternational.ISIJINT-2015-378.

[34] American Society for Testing and Materials. ASTM A370-17A. Test methods and definitions for mechanical testing of steel products. West Conshohocken: ASTM; 2017.

[35] American Society for Testing and Materials. ASTM E23-18. Standard test method for notched bar impact testing of metallic materials. West Conshohocken: ASTM; 2018. 
[36] Zhang L, Guo DC. A general etchant for revealing prior-austenite grain boundaries in steels. Materials Characterization. 1993;30(4):299305. http://dx.doi.org/10.1016/1044-5803(93)90078-A.

[37] Bouyne E, Flower HM, Lindley TC, Pineau A. Use of EBSD technique to examine microstructure and cracking in a bainitic steel. Scripta Materialia. 1998;39(3):295-300. http://dx.doi.org/10.1016/S1359-6462(98)00170-5.

[38] Li X, Ma X, Subramanian SV, Shang C. EBSD characterization of secondary microcracks in the heat affected zone of a X100 pipeline steel weld joint. International Journal of Fracture. 2015;193(2):131-139. http://dx.doi.org/10.1007/s10704-015-0024-3.

[39] Zhao H, Wynne BP, Palmiere EJ. Effect of austenite grain size on the bainitic ferrite morphology and grain refinement of a pipeline steel after continuous cooling. Materials Characterization. 2017;123:128-136. http://dx.doi.org/10.1016/j.matchar.2016.11.025.

[40] Li Y, Baker TN. Effect of morphology of martensite-austenite phase on fracture of weld heat affected zone in vanadium and niobium microalloyed steels. Materials Science and Technology. 2010;26(9):1029-1040. http://dx.doi.org/10.1179/026708309X12512744154360

[41] Lambert-Perlade A, Sturel T, Gourgues AF, Besson J, Pineau A. Mechanisms and modeling of clevage fracture in simulated heat-affected zone microstructures of a high-strengh low alloy steel. Metallurgical and Materials Transactions. A, Physical Metallurgy and Materials Science. 2004;35(3):1039-1053. http://dx.doi.org/10.1007/s11661-004-0030-y.

[42] Grabulov A, Petrov R, Zandbergen HW. EBSD investigation of the crack initiation and TEM-FIB analyses of the microstructural changes around the cracks formed under rolling contact fatigue (RCF). International Journal of Fatigue. 2010;32(3):576-583. http://dx.doi.org/10.1016/j.ijfatigue.2009.07.002.

[43] Nohava J, Haušild P, Karlík M, Bompard P. Electron backscattering diffraction analysis of secondary clevage cracks in a reactor pressure vessel steel. Materials Characterization. 2003;49(3):211-217. http://dx.doi.org/10.1016/S1044-5803(02)00360-1.

[44] Venegas V, Caleyo F, González JL, Baudin T, Hallen JM, Penelle R. EBSD study of hydrogen-induced cracking in API-5 L-X46 pipeline steel. Scripta Materialia. 2005;52(2):147-152. http://dx.doi.org/10.1016/j.scriptamat.2004.09.015.

[45] Jian H, Jiang F, Wei L, Zheng X, Wen K. Crystallographic mechanism for crack propagation in the T7451 Al-Zn-Mg-Cu alloy. Materials Science and Engineering A. 2010;527(21-22):5879-5882. http://dx.doi.org/10.1016/j.msea.2010.05.063.

[46] Gourgues AF. Electron back scattering diffraction study of acicular ferrite, bainite, and martensite steel microstrucutre. Materials Science and Technology. 2000;16(1):26-40. http://dx.doi.org/10.1179/026708300773002636.

[47] Mao G, Cayron C, Cao R, Logé R, Chen J. The relationship between low-temperature toughness and secondary crack in low-carbon bainitic weld metals. Materials Characterization. 2018;145:516-526. http://dx.doi.org/10.1016/j.matchar.2018.09.012.

[48] Subramani S, Ma X, Wang X, Shang C, Zhang X, Miao C, Collins L. Control of age shear area in DWTT at low temperature in niobium microalloyed line pipe steel. In: American Society of Mechanical Engineers. Proceeding of the 12th International Pipeline Conference; 2018 September 24-28; Calgary, Canada. New York, NY: The American Society of Mechanical Engineers; 2018. p. 10.

[49] Olasolo M, Uranga P, Rodriguez-Ibabe JM, López B. of austenite microstructure and cooling rate on transformation characteristics in a low carbon Nb-V microalloyed steel. Materials Science and Engineering A. 2011;528(6):2559-2569. http://dx.doi.org/10.1016/j.msea.2010.11.078.

[50] Zhu K, Bouaziz O, Oberbillig C, Huang M. An approach to define the effective lath size controlling yield strength of bainite. Materials Science and Engineering A. 2010;527(24-25):6614-6619. http://dx.doi.org/10.1016/j.msea.2010.06.061.

[51] Fan L, Zhou D, Wang T, Li S, Wang Q. Tensile properties of an acicular ferrite and martensite/austenite constituent steel with varying cooling rates. Materials Science and Engineering A. 2014;590:224-231. http://dx.doi.org/10.1016/j.msea.2013.10.037.

[52] Griffith AA. The phenomena of rupture and flow in solids. Philosophical Transactions of the Royal Society A. 1921;221:163-198.

[53] Naylor JP. The influence of the lath morphology on the yield stress and transition temperature of martensitic-bainitic steels. Metallurgical and Materials Transactions. A, Physical Metallurgy and Materials Science. 1979;10(7):861-873. http://dx.doi.org/10.1007/BF02658305.

[54] Shirahata H, Nakashima K, Inoue T, Ishida K, Funatsu Y, Okawa T, Yanagita K, Inami A, Minagawa M. YP 460 N/mm2 class heavy thick plate with excellent brittle crack arrestability for mega container ships. Nippon Steel \& Sumitomo Metal Technical. 2015;110:25-29. 